\title{
Charcot-Leyden crystals in a prostatic adenocarcinoma Özgür Aydın*
}

\author{
Address: Alanya Hospital, Department of Pathology, Başkent University, Alanya, Antalya, Turkey \\ Email: Özgür Aydın* - darkeetar@yahoo.com \\ * Corresponding author
}

Published: 07 September 2006

Diagnostic Pathology 2006, I:26 doi:10.1 I86/1746-1596-I-26
Received: 28 August 2006

Accepted: 07 September 2006

This article is available from: http://www.diagnosticpathology.org/content/I/I/26

(C) 2006 Aydin; licensee BioMed Central Ltd.

This is an Open Access article distributed under the terms of the Creative Commons Attribution License (http://creativecommons.org/licenses/by/2.0), which permits unrestricted use, distribution, and reproduction in any medium, provided the original work is properly cited.

\begin{abstract}
A transrectal needle biopsy from a 63-year-old man was decided because of a high prostatic spesific antigen in the blood, and a hard right lobe in rectal examination. 10 examples were taken from each lobe. In I of 4 of the examples from the left lobe, which contained a small focus of adenocarcinoma, numerous eosinophils were observed to surround the carcinomatous focus and attack the carcinoma cells. Uniquely, at the same focus Charcot-Leyden crystals could be seen in the intraluminal space and stromal area. A carcinoma oriented eosinophil accumulation, and CharcotLeyden crystals in prostate was not described before.
\end{abstract}

A transrectal needle biopsy was indicated due to a high level of prostatic spesific antigen in the blood, and a hard right lobe in rectal examination of a 63-year-old man. 10 examples were taken from each lobe of the prostate. In microscopic examination, all examples from the right lobe contained an adenocarcinoma covering 25 to $50 \%$ of the biopsies. Only 4 of the examples from the left lobe contained the tumor, which were all small focuses, composed of 8-10 glands. It was one of the biopsies from the left lobe with a small group of neoplastic glands that attracted our attention. Initially, it was the intraluminal bright, eosinophilic crystalloids as a striking low-power appearance. In daily practice, finding crystalloids in a transrectal needle biopsy with a prostatic adenocarcinoma should not be so astonishing. On the contrary, demonstration of intraluminal crystalloids is common in such cases, and even perceived to be an aid in the diagnosis of prostatic adenocarcinoma [1]. The neoplastic group was also incorporated with a dense infiltration of eosinophils. A carefull re-evaluation of other biopsies confirmed that the feature was peculiar to the aforementioned focus. The reaction, which seemed to be almost totally composed of eosinophils, was clearly restricted to the carcinomatous

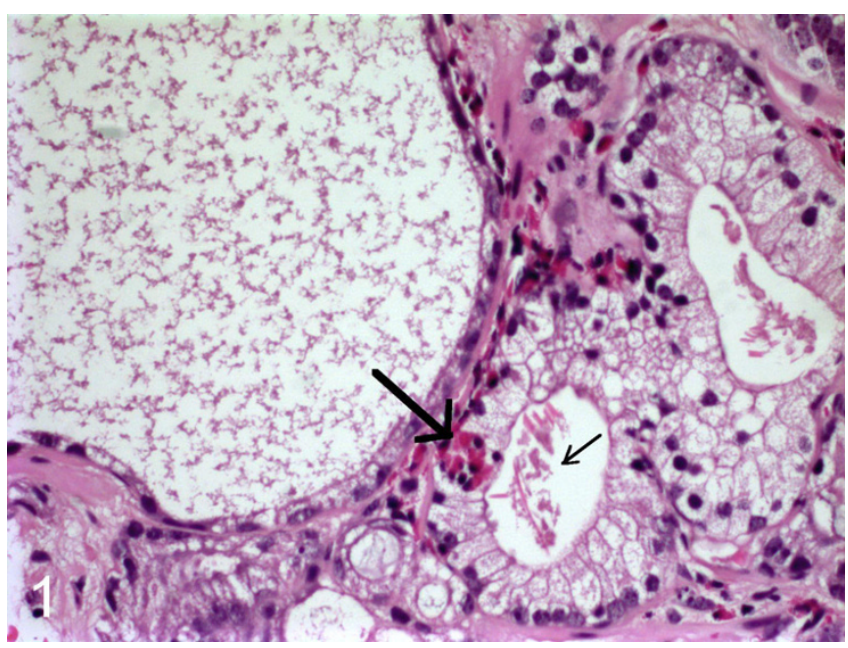

\section{Figure I}

The peritumor fibrous stroma contained degranulated eosinophils. An intraepithelial group of eosinophils is seen (thick arrow). Charcot-Leyden crystals were seen intraluminally (thin arrow). 


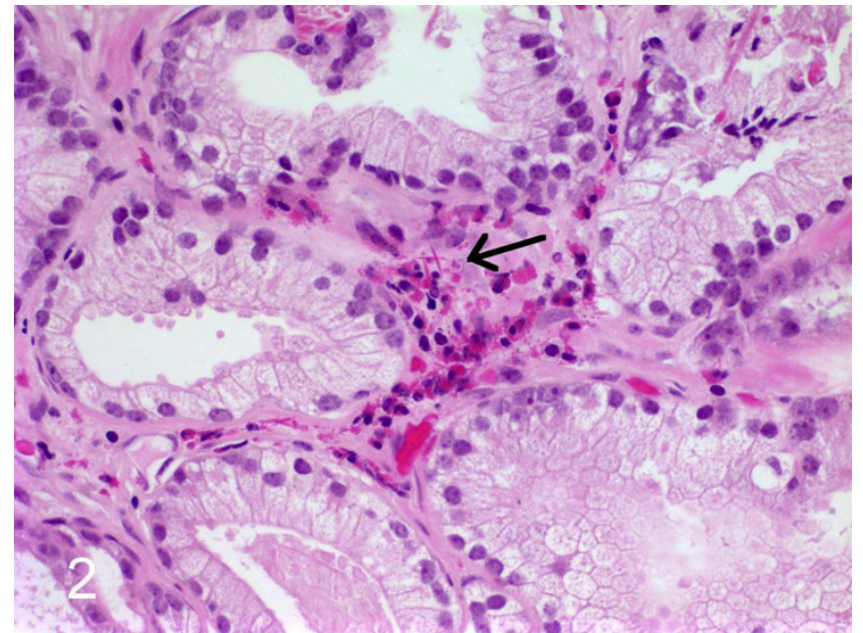

Figure 2

The crystals (arrow) could also be found in the stroma.

glandular group. Eosinophils were not only surrounding the focus but also looked like 'attacking' the carcinoma cells. Intraepithelial eosinophils forming occasional small groups could easily be found. The interglandular stroma was rich in free granules, an absolute evidence of eosinophil activation. The co-existance of the eosinophils and the crystalloids certainly pointed to a relationship between two. Actually, the crystalloids were extremely similar to the Charcot-Leyden crystals, that we were familiar with in many allergic situations. It was not unlikely, as these crystals were considered to be an other morphologic hallmark of eosinophil activation. When searched, the crystals could also be found in the stroma.

Charcot-Leyden crystals are known to be composed of a single protein, released by the activated eosinophil, called lysolecithin acylhydrolase, which has lysophospholipase activity. Lysolecithin acylhydrolase is one of several eosinophil proteins with cytotoxic properties involved in the eosinophil's antiparasitic, antineoplastic, and immune functions [2]. In this case, co-existing eosinophil accumulation, degranulation and extraluminal presentation gave us confidence to call the bodies as Charcot-Leyden crystals. Morphological and histochemical searches indicate that the intraluminal contents (all crystalloids, corpora amylacea, and others) in benign and malignant glands form a continuous spectrum and are largely composed of material derived from the components of lining cells [3]. Naturally, they are observed as glandular intraluminal contents.

The homogenous nature of the infiltration suggested that such an infiltration might be induced by a tumor-derived eosinophil chemotactic factor. An explanation for this could be an extra-step mutation that caused a release of the stimulating factor that enhanced eosinophil chemotaxis.

The point is; this isolated focus, which did not show any histomorphologic difference from the other neoplastic tissue, was subject to an "selective" attemp of destruction by a spesific subgroup of the cellulary host defence. This feature might be inspiring in developing approaches towards enhanced management strategies for cancer treatment [4].

\section{References}

I. Varma M, Lee MW, Tamboli P, Zarbo RJ, Jimenez RE, Salles PGO, Amin MB: Morphologic Criteria for the Diagnosis of Prostatic Adenocarcinoma in Needle Biopsy Specimens.A Study of 250 Consecutive Cases in a Routine Surgical Pathology Practice. Arch Pathol Lab Med 2002, I 26(5):554-56I.

2. Weller PF, Goetzl EJ, Austen KF: Identification of human eosinophil lysophospholipase as the constituent of Charcot-Leyden crystals. Proc Natl Acad Sci 1980, 77:7440-7443.

3. Drachenberg CB, Papadimitriou JC: Prostatic corpora amylacea and crystalloids: similarities and differences on ultrastructural and histochemical studies. J Submicrosc Cytol Pathol 1996, 28(2): | $4 \mid-50$.

4. Nelson WG, Simons JV, Mikhak B, Chang JF, DeMarzo AM, Carducci MA, Kim M, Weber CE, Baccala AA, Goeman MA, Clift SM, Ando DG, Levitsky HI, Cohen LK, Sanda MG, Mulligan RC, Partin AW, Carter HB, Piantadosi S, Marshall FF: Cancer cells engineered to secrete granulocyte-macrophage colony-stimulating factor using ex vivo gene transfer as vaccines for the treatment of genitourinary malignancies. Cancer Chemother Pharmacol 2000, 46(Suppl):67-72.
Publish with Biomed Central and every scientist can read your work free of charge

"BioMed Central will be the most significant development for disseminating the results of biomedical research in our lifetime. " Sir Paul Nurse, Cancer Research UK

Your research papers will be:

- available free of charge to the entire biomedical community

- peer reviewed and published immediately upon acceptance

- cited in PubMed and archived on PubMed Central

- yours - you keep the copyright

Submit your manuscript here:

http://www.biomedcentral.com/info/publishing_adv.asp
BiolMedcentral 